\title{
Why oral calcium supplements may reduce renal stone disease: report of a clinical pilot study
}

\author{
C P Williams, D F Child, P R Hudson, G K Davies, M G Davies, R John, P S Anandaram, \\ A R De Bolla
}

Department of Medical Biochemistry, Wrexham Maelor Hospital NHS Trust, Wrexham LL13 7TD, UK

C P Williams

P R Hudson

G K Davies

M G Davies

Department of Medicine, Wrexham Maelor Hospital NHS Trust

D F Child

Department of Urology, Wrexham Maelor Hospital NHS Trust

P S Anandaram

A R De Bolla

Department of Medical Biochemistry, University Hospital of Wales Healthcare NHS Trust, Heath Park, Cardiff, CF4 4XW, UK R John

Correspondence to: Dr Williams

clive.williams@

new-tr.wales.nhs.uk

Accepted for publication 11 May 2000

\begin{abstract}
Aims-To investigate whether increasing the daily baseline of gut calcium can cause a gradual downregulation of the active intestinal transport of calcium via reduced parathyroid hormone (PTH) mediated activation of vitamin $D$, and to discuss why such a mechanism might prevent calcium oxalate rich stones. To demonstrate the importance of seasonal effects upon the evaluation of such data.
\end{abstract}

Methods-Within an intensive 24 hour urine collection regimen, daily calcium supplementation $(500 \mathrm{mg})$ was given to five stone formers for a 10 week period during a six month crossover study. In a further population of patients on follow up for previous renal stone disease, observations were made on 106624 hour urine samples collected over five years in respect of seasonal effects relevant to the interpretation of the study.

Results-In the group of patients on calcium supplements the following results were found. During calcium supplementation, the proportion of urine calcium to oxalate was higher (increased calcium to oxalate molar ratio), the 24 hour urine product of calcium and oxalate did not rise, and urine oxalate was lower during the first six weeks of supplementation. Twenty four hour urine calcium was $10.2 \%$ higher than baseline in the final four weeks of the 10 weeks of supplementation. Twenty four hour urine phosphate was $11.4 \%$ lower during the first six weeks of supplementation, but then rose while the patients were still on supplementation; renal tubular reabsorption of phosphate (TmP/GFR) mirrored the urine phosphate changes inversely. PTH was higher after stopping supplementation, but 1,25$(\mathrm{OH})_{2}$-cholecalciferol changes were not detected. In the 1066 urine samples collected over five years the following results were found. Calcium and oxalate excretion correlated positively and not inversely. Urine calcium and phosphate excretion were $5.5 \%$ and $2.5 \%$ higher, respectively, in "light" months of the year compared with "dark" months. A post summer decline in both urine calcium and urine phosphate was relevant to the interpretation of the study.

Conclusions-Regular calcium supplementation does not raise the product of calcium and oxalate in urine and the proportion of oxalate to calcium is reduced.
The underlying mechanisms of the changes seen in phosphate, calcium, and PTH and the observations on $1,25-(\mathrm{OH})_{2}-$ cholecalciferol are not clear. Observed changes in phosphate could possibly be part of a calcium regulating feedback loop operating over a period of weeks. In evaluating these mechanisms background seasonal effects are important. It is possible that "programming" of the gut mucosa in terms of calcium transport is a major determinant of the relation between calcium and oxalate concentrations in urine and their relative abundance. Increased oral calcium, in association with a reduction of the relative proportion absorbed, may be pertinent to the prevention of calcium oxalate rich stones.

(f Clin Pathol 2001;54:54-62)

Keywords: renal stones; calcium oxalate product; dietary calcium; renal tubular reabsorption of phosphate

Humans evolved in a calcium rich environment before the advent of farming 10000 years ago. Few renal stones are associated with early skeletal remains, ${ }^{1}$ yet the consumption of calcium by early humans was three to five times that of people in modern industrialised countries, where up to $10 \%$ of men and $3 \%$ of women have renal stones at some time in their life..$^{2-6}$ Why should this be? A major prospective study by Curhan et al in North America showed in a cohort of 45000 men that the risk of symptomatic stone disease was less for those with higher dietary calcium. ${ }^{7}$ Previous dietary work concentrated upon avoiding the saturation of urine by using low calcium and low oxalate diets, ${ }^{8}$ but dietary evidence increasingly shows that a higher intake of calcium is associated with lower urinary oxalate and decreased renal stone formation. ${ }^{9-16}$ Our traditional focus upon reducing calcium intake in renal stone formers now seems to be inappropriate. In a recent study $^{17}$ of 34 stone formers prescribed a low calcium diet for 30 days, there was a pronounced increase in urine oxalate, with a deleterious effect on relative supersaturation of calcium oxalate. If the extremely complex process of calcium regulation evolved to cope with a different calcium supply to the present one, are we simply at the design limits of the regulatory process or overriding components of it by vitamin D supplementation? Fraser $^{18}$ notes that none of the terrestrial land based vertebrates maintain their vitamin $\mathrm{D}$ status from a nutritional source, but as little as $25 \mu \mathrm{g}$ (1000 IU) of vitamin D has been shown to be 


\begin{tabular}{|c|c|c|c|c|c|}
\hline Period 1 & Period 2 & & Period 3 & Period 4 & Period 5 \\
\hline 4 weeks & $\begin{array}{l}6 \text { weeks } \\
500 \mathrm{mg} \\
\text { calcium }\end{array}$ & & $\begin{array}{l}4 \text { weeks } \\
500 \mathrm{mg} \\
\text { calcium }\end{array}$ & 6 weeks & 4 weeks \\
\hline $\begin{array}{l}\text { Urine } \\
8 \times 24 \mathrm{~h} \\
\text { Serum } \\
\times 4\end{array}$ & $\begin{array}{l}\text { Urine } \\
3 \times 24 \mathrm{~h} \\
\text { Serum } \\
\times 3\end{array}$ & & $\begin{array}{l}\text { Urine } \\
8 \times 24 \mathrm{~h} \\
\text { Serum } \\
\times 4\end{array}$ & $\begin{array}{l}\text { Urine } \\
3 \times 24 \mathrm{~h} \\
\text { Serum } \\
\times 3\end{array}$ & $\begin{array}{l}\text { Urine } \\
8 \times 24 \mathrm{~h} \\
\text { Serum } \\
\times 3\end{array}$ \\
\hline JUN & JUL & AUG & SEP & OCT & NOV \\
\hline
\end{tabular}

Figure 1 Illustration of the trial design showing the periods when calcium supplements were given and the timing of blood and urine samples.

causally associated with stones. ${ }^{19}$ We have personally noted with concern the number of our patients who have taken vitamin $\mathrm{D}$ before their stone episode, and a correlation between 1,25-
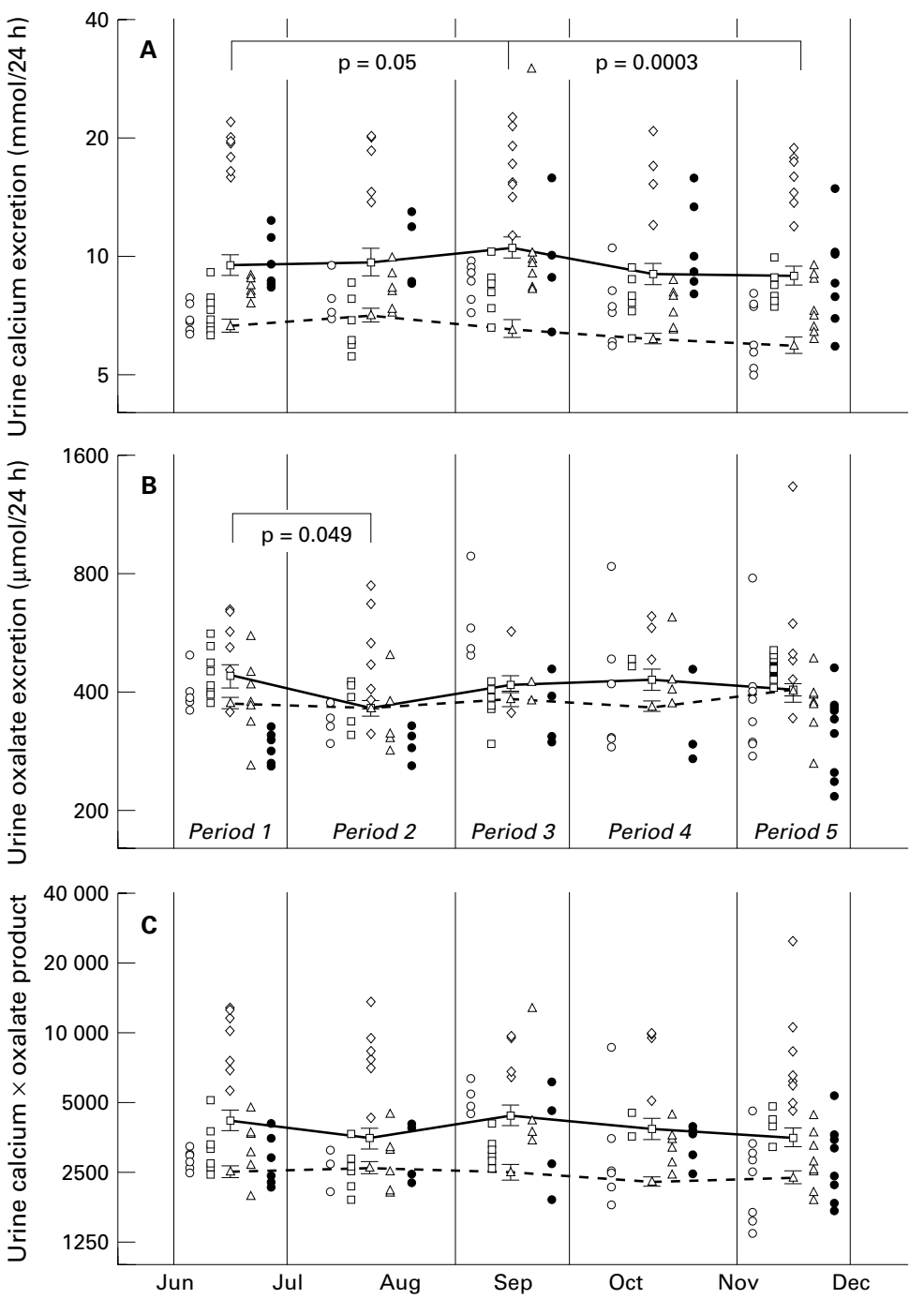

Figure 2 Patients' results showing $\log _{10}$ transformed values for 24 hour urine $(A)$ calcium excretion, $(B)$ oxalate excretion, and $(C)$ the calcium times oxalate product excretion. The five patients' results are represented by open circles, open squares, open diamonds, open triangles, and filled circles, respectively. In the interests of clarity, individual patients' results during each stage of the trial are simply stacked one above the other, rather than being depicted chronologically. Separate patients' results are depicted side by side to assist in interpreting the data. The solid lines represent the overall mean patients' results for periods 1,2, 3, 4, and 5 of the trial. Error bars represent $1 S E$ about the mean. The broken lines represent overall mean values of patients from the reference population, whose urine samples were collected during the same weeks of the year as the trial patients. Significant differences between periods are only shown for the trial patients and were calculated by two way analysis of variance, followed by the Fisher LSD test.
$(\mathrm{OH})_{2}$-cholecalciferol and urine calcium and urine oxalate has been demonstrated ${ }^{20}$ in stone formers.

About $80 \%$ of renal stones are predominantly composed of calcium oxalate ${ }^{2}$ and up to half the patients have hypercalciuria. ${ }^{2}$ In this group, preventative treatment has traditionally reduced the oral intake of both calcium and oxalate. The risk, however, of controlling calcium at the expense of oxalate has been emphasised because calcium oxalate saturation increases rapidly with a small increase in urine oxalate. ${ }^{3}$ Small increases in urine oxalates are much more important for augmenting the risk of stones than are large increases in urine calcium. A detailed review of this area can be found in Robertson and Peacock (1980). ${ }^{21}$

A major impediment to this study has been the recruitment of individuals willing to take calcium supplements against a traditional practice resolutely to the contrary. Our objective was to find out whether increasing the daily baseline of calcium reaching the gut might gradually cause a downregulation of the processes governing active intestinal transport of calcium by a reduction of parathyroid hormone $(\mathrm{PTH})$ mediated conversion of $25-(\mathrm{OH})$-cholecalciferol to $1,25-(\mathrm{OH})_{2}$-cholecalciferol. In a previous study, ${ }^{22}$ our key observations were the following: (1) during oral calcium loading, renal stone formers as a group exhibit a greater degree of phosphaturia for any given serum calcium concentration than control subjects; and (2) mean $1,25-(\mathrm{OH})_{2}$-cholecalciferol was higher in the stone formers. Of particular relevance, Alvarez-Arroyo and colleagues ${ }^{23}$ suggested that serum phosphate values are lower in patients with absorptive hypercalciuria and raised 1,25$(\mathrm{OH})_{2}$-cholecalciferol. As essential background to these observations, there is strong evidence that phosphate has a major role in the regulation of the concentration of $1,25-(\mathrm{OH})_{2}-$ cholecalciferol. In essence, decreased availability of phosphate increases 1,25- $(\mathrm{OH})_{2}{ }^{-}$ cholecalciferol $^{24}$ and hypophosphataemia is associated with high $1,25-(\mathrm{OH})_{2}$-cholecalciferol values. ${ }^{25} 26$

The renal tubular reabsorption of phosphate (TmP/glomerular filtration rate (GFR)), ${ }^{27} \mathrm{de}-$ scribed as the "renal threshold phosphate concentration", has been used in this study as a presumptive index of the physiological effect of PTH on phosphate excretion. TmP/GFR is independent of GFR and the net inflow of phosphate into the intracellular space from bone, gut, and soft tissue. An extensive review by Crook and Swaminatham of disorders of plasma phosphate ${ }^{25}$ cites TmP/GFR as the best measure of renal tubular absorption of phosphate, of which PTH is the major hormonal regulator..$^{25}$ Problems in the interpretation of $\mathrm{TmP} / \mathrm{GFR}$ values are emphasised in a comprehensive review by Payne $^{28}$; tubular damage might affect phosphaturia and the possibility exists of a specific phosphaturic hormone. ${ }^{28-30}$ This putative hormone is a fundamental unknown variable in this context, limiting all conclusions.

Stanniocalcin ${ }^{31}$ is a phosphate and calcium transport protein recently recognised in bony 
fish, but also encoded by the human genome. It is known experimentally to stimulate mucosal phosphate absorption in mammals and is a further important unknown factor.

Our present study was undertaken to determine what effects calcium supplements might have upon calcium and oxalate in urine. We measured the molar ratio of calcium to oxalate and the calcium and oxalate product. This product is a very "crude" index for clinical purposes because it does not test the supersaturation of urine with respect to calcium oxalate. It does not allow for complexing of oxalate by calcium; this latter phenomenon is the factor that has the most effect on the free ion concentration of oxalate and is the main
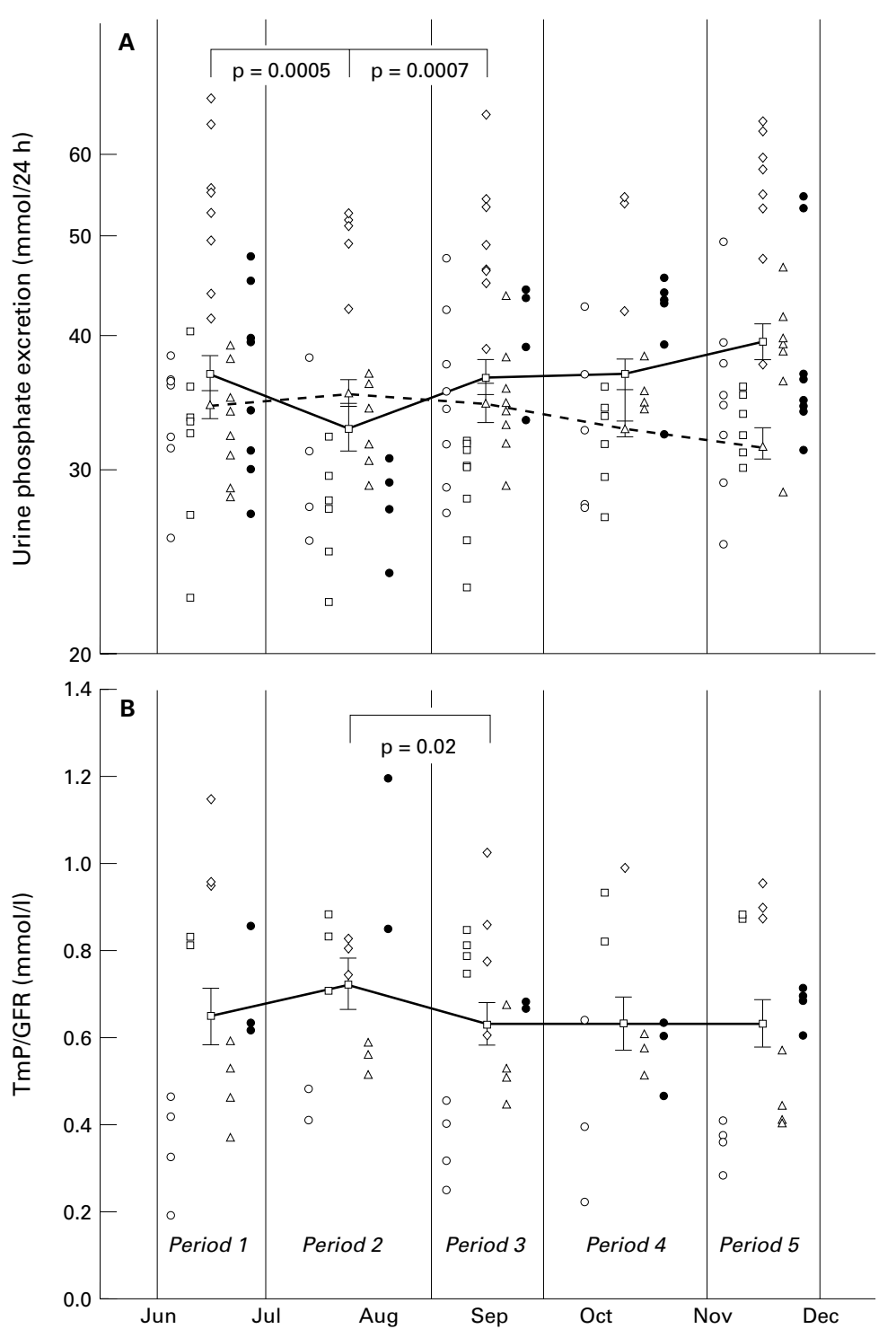

Figure 3 Pooled patients' results showing $\log _{t 0}$ transformed values for $(A) 24$ hour urine phosphate excretion and (B) renal tubular reabsorption of phosphate (TmP/GFR ratio). Individual patients' results are represented by open circles, open squares, open diamonds, open triangles, and filled circles, respectively. In the interests of clarity, individual patients' results during each stage of the trial are simply stacked one above the other, rather than being depicted chronologically. Separate patients' results are depicted side by side to assist in interpreting the data. The solid lines show the mean results for periods 1, 2, 3, 4, and 5 of the trial. The broken lines represent overall mean values of patients from the reference population, whose urine samples were collected during the same weeks of the year as the trial patients. Error bars represent 1 SE about the mean. Significant differences between periods are only shown for the trial patients and were calculated by two way analysis of variance, followed by the Fisher LSD test. determinant of the supersaturation of urine with respect to calcium oxalate under normal situations. However, the calcium and oxalate product does afford an insight into the overall regulation of calcium and oxalate metabolism, and the molar ratio indicates the relative proportions of calcium and oxalate. We explore the thesis that stone formers might "over react" to the relative calcium starvation of the modern diet with phosphaturia, and investigate the possibility of reducing their phosphaturia and downregulating cholecalciferol activation by means of sustained calcium supplementation. Such a mechanism could lead to less calcium being absorbed, which would raise the proportion of oxalate "trapped" in the gut. The season of the year is well known to affect calcium and possibly oxalate excretion, and for this reason we have abstracted data over five years to compensate for natural background effects relating to the period of the patient study and to indicate the overall magnitude of such changes. Extensive work undertaken during the 1970 s by Rose ${ }^{32} 33$ in London and the mineral metabolism unit at Leeds, ${ }^{34}{ }^{35}$ and later by others, demonstrates raised calcium in the summer and usually raised oxalate. Although urine phosphate appeared to be higher in the summer, there were no significant seasonal differences in 246 male stone formers in observations by Robertson, ${ }^{35}$ and there were no differences in a study of UK doctors, ${ }^{36}$ or in 147 institutionalised elderly patients. ${ }^{37}$ Urine phosphate was lower in the March to August period of the year in 118 male stone formers on a "free diet" reported by Juuti et al. ${ }^{38}$

\section{Methods}

SELECTION OF PATIENTS

Eight male patients with confirmed renal stones were recruited to the study and five completed it. Their ages ranged from 44 to 63 years. All exhibited hypercalciuria (calcium $>7.5 \mathrm{mmol} / 24$ hours) and hyperoxaluria (oxalate $>400 \mu \mathrm{mol} / 24$ hours) at some time during their management. Urinary tract anatomical defects, hyperuricosuria, renal tubular acidosis, and cystinuria were excluded. Patients did not receive medication in the three months preceding our study.

In a further study, the results of 24 hour urine collections of all patients on regular follow up for renal stone disease over the previous five years were collected on to a database. All patients with less than two samples collected within this period were excluded. Because patients had been instructed to maintain a 24 hour urinary volume of around 2.5 litres, those samples with volumes less than 2 litres and greater than 3 litres were rejected, to exclude urine samples that might have been overcollected and undercollected. In addition, results from a patient known to have malabsorption were excluded. The resulting database comprised 246 patients and a total of 1066 individual urine collections. For the purposes of statistical analysis, the samples were coded as to whether they were collected during the "light" months of the year (May to October) or the "dark" months, and they were also coded 

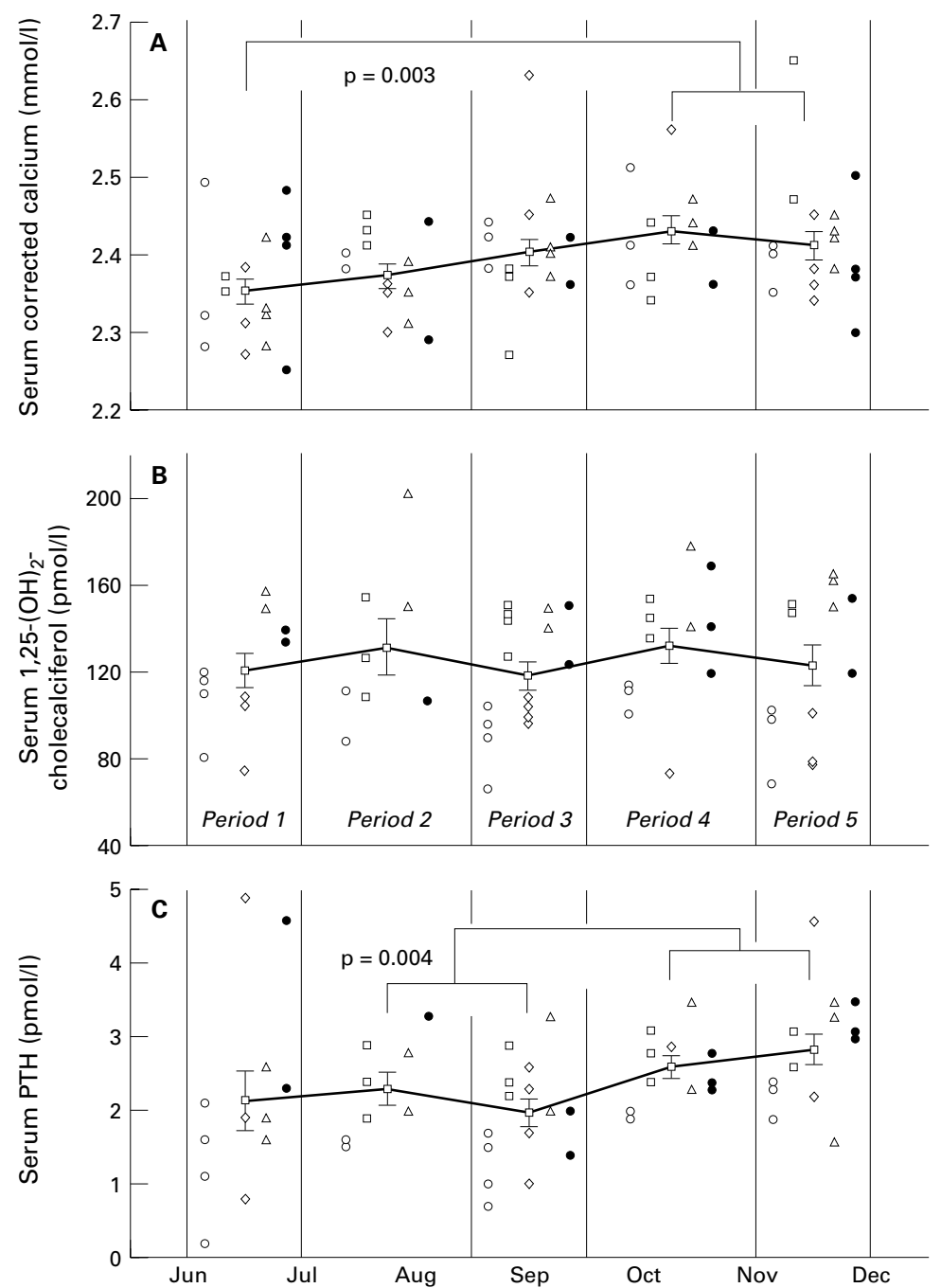

Figure 4 Pooled patients' results showing (A) serum calcium, (B) serum 1,25-(OH),-cholecalciferol, and $(C)$ serum parathyroid hormone $(P T H)$. The five patients' results are represented by open circles, open squares, open diamonds, open triangles, and filled circles, respectively. In the interests of clarity, individual patients' results during each stage of the trial are simply stacked one above the other, rather than being depicted chronologically. Separate patients' results are depicted side by side to assist in interpreting the data. The solid lines show the mean results for periods 1,2,3, 4, and 5 of the trial. Error bars represent 1 SE about the mean. Significant differences between periods were calculated by two way analysis of variance, followed by the Fisher LSD test. For the purpose of statistical analysis, results for periods 2 and 3 (on calcium supplements) and periods 4 and 5 (off calcium supplements) were pooled.

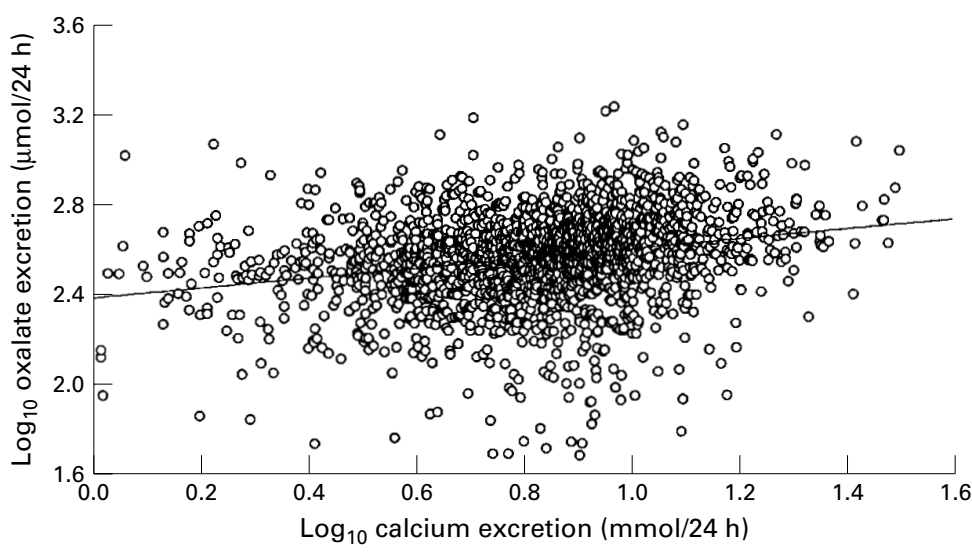

Figure 5 Scatter diagram of log 24 hour urine oxalate excretion against log calcium excretion on data from a group of 1066 urine collections from patients on follow up for previous renal stone disease. The regression parameter associated with the regression line was 0.155 ( $95 \%$ confidence interval, 0.045 to $0.266 ; p=0.006$ ).
" 1 " to " 5 " if they were collected at the same time of the year as the periods of the trial (June to July, July to mid August, mid August to mid September, mid September to November, and November to December, respectively). The purpose of collecting these data was to test for an overall correlation between calcium and oxalate and to demonstrate background changes in calcium, oxalate, and phosphate that might have a bearing on the interpretation of the data from our patient study group.

STUDY DESIGN

Ethics committee approval was obtained for our study. Figure 1 depicts the five periods of our study. Periods 1, 3, and 5 represent steady states subject to the effects of background factors. During periods 2 and 3,500 $\mathrm{mg}$ of calcium was added in the morning to the patients' normal diet as one Calcichew tablet (Shire Pharmaceuticals Ltd, Hampshire, UK). During periods 2 and 4 , changes occurred in the equilibrium corresponding to starting or stopping calcium supplements, respectively. Six weeks (the length of these periods) was "allowed" for this prospectively, on the basis of clinical experience in the use of cholecalciferol and delay in reaching calcium equilibrium from dose adjustment. We assumed that in the achievement of a steady state the processes of response to a change in calcium intake will feedback in some manner on cholecalciferol.

Eight 24 hour urine samples were collected in each of periods 1,3 , and 5 , together with six in each of periods 2 and 4 . Four samples of serum were collected in each of periods 1,3 , and 5, and three samples in each of periods 2 and 4 . Abdominal $x$ ray was performed within three months before and after completion of our study. Patients maintained a urine output of at least 2.5 litres $/ 24$ hours; they were equipped with a measuring cylinder and urine volume chart as part of their standard management. They were asked not to make any changes to their overall dietary practices. None were or had been on calcium restricted diets.

\section{LABORATORY ANALYSES}

Calcium, albumin, phosphate, and creatinine were measured by standard laboratory procedures (Synchron CX7; Beckman Instruments (UK) Ltd, High Wycombe, Buckinghamshire, UK). Serum calcium was corrected for the serum albumin concentration using a relation derived from a local population study: corrected calcium $=$ serum total calcium $\times($ albu$\min \times 0.017)+0.692 . \mathrm{TmP} / \mathrm{GFR}$ was calculated $^{28}$ from serum phosphate and creatinine results and from a contemporaneous 24 hour urine. Urine oxalate was measured by a commercial oxalate oxidase method (catalogue number 591-C; Sigma-Aldrich Co Ltd, Poole, Dorset, UK). The urine calcium times oxalate product was calculated by multiplying together the respective 24 hour urinary excretions and is expressed in the text without units; the urine calcium to oxalate ratio was calculated by simple division and is expressed as $\mathrm{mmol} / \mathrm{mmol}$. Intact PTH was measured by a two site immunochemiluminometric assay (Chiron Diagnostics 
Table 1 Phosphate, calcium, and oxalate excretion and calcium $\times$ oxalate product in 1066 individual 24 hour urine samples collected by 246 patients over a five year period

\begin{tabular}{|c|c|c|c|c|}
\hline & Calcium $\times$ oxalate & $\begin{array}{l}\text { Calcium excretion } \\
(\mathrm{mmol} / 24 \mathrm{~h})\end{array}$ & $\begin{array}{l}\text { Phosphate excretion } \\
(\mathrm{mmol} / 24 \mathrm{~h})\end{array}$ & $\begin{array}{l}\text { Oxalate excretion } \\
(\mu \mathrm{mol} / 24 \mathrm{~h})\end{array}$ \\
\hline Dark period & 2372 (2270 to 2477$)$ & $6.37(6.18$ to 6.56$)$ & $32.5(31.7$ to 33.1$)$ & 372 (363 to 382 ) \\
\hline Light period & 2493 (2388 to 2602 ) & $6.72(6.52$ to 6.91$)$ & 33.3 (32.6 to 34.0 ) & 371 (361 to 381 ) \\
\hline p Values & $\mathrm{p}=0.02$ & $\mathrm{p}<0.0001$ & $\mathrm{p}=0.01$ & Not significant \\
\hline
\end{tabular}

Samples were coded "dark" and "light" according to whether they were collected November to April or May to October, respectively.

Mean results are given with $95 \%$ confidence intervals.

p Values refer to the effect of the time of year in a two way ANOVA (results classified by "patient number" and by "time of year").

Ltd, Halstead, Essex, UK) and 1,25-(OH) ${ }_{2}^{-}$ cholecalciferol by radioimmunoassay (Immunodiagnostic Systems, Bolton, Tyne and Wear, UK).

STATISTICAL METHODS

All statistical calculations were performed using the general linear modelling module of the Statistica for Windows 1999 edition package (StatSoft Inc, Oklahoma, USA). Patients' urinary calcium, oxalate, and phosphate excretions and calcium times oxalate products showed skewed distributions and were logarithmically transformed. Therefore, mean values of urinary analytes (and their standard errors and 95\% confidence intervals (CI)) were calculated before transformation back to geometric means. In the text and figures, these mean values, standard errors, and 95\% CI values were calculated simply from pooled values within each stage. However, because of large interindividual differences, the categorical variable "patient number" was included in all analysis of variance (ANOVA) models together with other categorical or continuous variables. The Fisher LSD test was used to test a priori hypotheses about difference between the periods of the trial. In view of the relatively small numbers of blood samples collected in each period, it was necessary in some cases to pool data from periods 2 and 3 ("on calcium") and 4 and 5 ("off calcium") simply by re-coding the observations as if they were from the same period.

In the series of 1066 patients' results, an ANOVA model with a categorical (patient number) and continuous variable ("log calcium excretion") was used to assess the relation between calcium and oxalate excretion. In this same dataset, two way ANOVA was used to assess the differences between light and dark collections and between samples collected at the same time of year as the trial samples. In this case, the Bonferroni test was used to assess differences between periods because there were no particular a priori hypotheses to be tested.

\section{Results}

Mean calcium excretion was higher in period 3 on supplements $(10.41 \mathrm{mmol} / 24$ hours; $95 \%$ CI, 9.20 to 11.79 ) than either baseline period 1 (9.45 mmol/24 hours; $95 \% \mathrm{CI}, 8.37$ to 10.68 ) or period $5(8.74 \mathrm{mmol} / 24$ hours; $95 \% \mathrm{CI}$, 7.79 to 9.81 ) when the patients were off calcium supplements (fig $2 \mathrm{~A}$ ). Urine oxalate excretion fell to $361 \mu \mathrm{mol} / 24$ hours $(95 \% \mathrm{CI}$, 331 to 396 ) in period 2 (on calcium supplements), compared with the baseline period 1 ( $406 \mu \mathrm{mol} / 24$ hours; $95 \% \mathrm{CI}, 375$ to 440 ; fig 2B). The urine calcium times oxalate product fell to 3465 (95\% CI, 2796 to 4294 ) in period 2 (on calcium supplements) from a baseline figure of 3826 (95\% CI, 3208 to 4561) in period 1 (fig 2C), but this did not reach significance. In contrast, the urine calcium to oxalate ratio rose from a baseline value of $24.8 \mathrm{mmol} /$ $\mathrm{mmol}(95 \% \mathrm{CI}, 21.6$ to 28.0 ) to a value of 28.1 (95\% CI, 24.1 to $32.2 ; \mathrm{p}=0.03$ ) in period 2 and $27.8(95 \% \mathrm{CI}, 21.8$ to $33.8 ; \mathrm{p}=0.049)$ in period 3.

Mean urine phosphate fell from a baseline value of $36.9 \mathrm{mmol} / 24$ hours $(95 \% \mathrm{CI}, 33.8$ to 39.8 ) to 32.7 (95\% CI, 29.5 to 36.3 ) in period 2 (on calcium supplements; fig 3A). This change was mirrored by an apparent increase in TmP/GFR from $0.65 \mathrm{mmol} /$ litre $(95 \% \mathrm{CI}$, 0.51 to 0.78 ) in the baseline period to 0.72 ( $95 \% \mathrm{CI}, 0.59$ to 0.85 ) in period 2 (fig 3B).

To increase the statistical power of between period tests of serum components, the data for periods 2 and 3 (on calcium supplements) and periods 4 and 5 (off calcium supplements) were pooled. Mean serum calcium rose to $2.42 \mathrm{mmol} /$ litre $(95 \% \mathrm{CI}, 2.39$ to 2.45$)$ in

Table 2 Phosphate, calcium, and oxalate excretion in 1066 individual 24 hour urine samples collected by 246 patients over a five year period

\begin{tabular}{lllll}
\hline & $\begin{array}{l}\text { Phosphate excretion } \\
(\text { mmol/24 } h)\end{array}$ & $\begin{array}{l}\text { Calcium excretion } \\
(\text { mmol/24 } h)\end{array}$ & $\begin{array}{l}\text { Oxalate excretion } \\
(\mu m o l / 24 h)\end{array}$ & Calcium $\times$ oxalate product \\
\hline Period 1 & $34.5(32.5$ to 36.7$)$ & $6.6(6.2$ to 7.1$)$ & $375(352$ to 400$)$ & $2496(2239$ to 2782$)$ \\
Period 2 & $35.5(33.8$ to 37.3) & $7.0(6.5$ to 7.6$)$ & $368(347$ to 392$)$ & $2586(2327$ to 2874$)$ \\
Period 3 & $34.7(31.9$ to 37.7$)$ & $6.5(5.9$ to 7.1$)$ & $381(3347$ to 418$)$ & $2468(2139$ to 2848$)$ \\
Period 4 & $32.7(31.5$ to 33.8$)$ & $6.1(5.8$ to 6.4$)$ & $364(345$ to 385$)$ & $2231(2060$ to 2417$)$ \\
Period 5 & $31.4(29.8$ to 33.1) & $5.8(5.3$ to 6.4$)$ & $398(372$ to 427$)$ & $2325(2065$ to 2618$)$ \\
p Values & $1 v 5, \mathrm{p}<0.01$ & $1 v 4, \mathrm{p}<0.01$ & & $2 v 4, \mathrm{p}<0.01$ \\
& $2 v 4, \mathrm{p}<0.001$ & $1 v 5, \mathrm{p}<0.001$ & & \\
& $2 v 5, \mathrm{p}<0.001$ & $2 v 4, \mathrm{p}<0.0001$ & & \\
& & $2 v 5, \mathrm{p}<0.001$ & & \\
\hline
\end{tabular}

Samples were coded " 1 " to " 5 " if they were collected at the same time of the year as the periods of the trial (June to July, July to mid August, mid August to mid September, mid September to November, and November to December, respectively). Mean results are presented with $95 \%$ confidence intervals.

p Values were assessed using the Bonferroni post to hoc test after two way ANOVA (results classified by "period number" and "patient number"). 
periods 4 and 5, compared with 2.35 (95\% CI, 2.31 to 2.39 ) in the baseline period 1 (fig $4 \mathrm{~A}$ ). There was no significant change in serum 1,25 $-(\mathrm{OH})_{2}$-cholecalciferol throughout the study (fig $4 \mathrm{~B}$ ). Serum PTH rose to a mean value of $2.74 \mathrm{pmol} /$ litre (95\% CI, 2.43 to 3.04 ) in periods 4 and 5 , compared with $2.08 \mathrm{pmol} /$ litre ( $95 \%$ CI, 1.73 to 2.44 ) in periods 2 and 3 (fig $4 \mathrm{C})$.

In the 1066 individual 24 hour urines collected by 246 patients on follow up for previous renal stone disease over a five year period, the effect of categorical (patient number) and continuous (log calcium excretion) variables upon "log oxalate excretion" was tested using an ANOVA model. The results showed an increase in urine oxalate excretion with increasing calcium excretion (fig 5). The regression parameter associated with "log calcium excretion" was 0.155 (95\% CI, 0.045 to $0.266 ; \mathrm{p}=0.006$ ).

In this population, there was a rise in urine phosphate excretion from $32.5 \mathrm{mmol} / 24$ hours in the dark months of the year to $33.3 \mathrm{mmol} / 24$ hours in the light months (table 1). Similarly, there was a rise in calcium excretion from $6.37 \mathrm{mmol} / 24$ hours to $6.72 \mathrm{mmol} / 24$ hours and a rise in the calcium times oxalate product from 2372 to 2493. There was no change in oxalate excretion. From the data presented in table 2, calcium and phosphate excretion would "normally" be lower in periods 4 or 5 of the trial (mid September to December), compared with results from earlier in the summer (June to August). Oxalate did not show any change within this time interval. The overall trends are depicted in the broken lines in figs $2 \mathrm{~A}, 3 \mathrm{~A}$, and $2 \mathrm{C}$, respectively.

\section{Discussion}

Two key observations have been made in this pilot group of stone formers, namely: (1) on $500 \mathrm{mg}$ oral calcium supplements, the molar ratio of calcium to oxalate increased in urine without raising the calcium times oxalate product and (2) the urine phosphate fell 10\% during the first six weeks of calcium supplementation, rising thereafter while remaining on supplements. Also of key relevance, in a further 246 stone formers, 24 hour urine calcium and oxalate were positively correlated. The observation that these two variables are not inversely related, as in feeding experiments (described below), is important to the discussion as are background seasonal changes in calcium and, in particular, phosphate.

The recruitment of individuals willing to keep up the programme of 24 hour urine collections was difficult. Within our clinic, intra-individual variation in 24 hour urine calcium and oxalate occurs by up to a factor of four over several months, and volunteers are not willing to undertake the number of 24 hour urine collections necessary to compensate for natural variation. Under the study conditions, urine oxalate excretion varied by a factor of up to eight in a single patient within a single period. This limits the statistical strength of the data.
Calcium and oxalate exist in the gut as free calcium and oxalate ions in equilibrium with the sparingly soluble calcium oxalate complex formed by the chelation of calcium by oxalate. ${ }^{39}$ In short term feeding experiments and dietary observations a low calcium diet raises urine oxalate and vice versa. ${ }^{15} 1640$ However, we found that calcium and oxalate are positively correlated in urine. How can this be reconciled with the gut chelation process? Regulation of calcium absorption by the gut mucosa would explain this paradox-a decreased proportion of calcium absorbed in the gut would reduce urine calcium excretion and retain calcium in the gut to be chelated by oxalate. Changes in the true proportion of calcium being absorbed would therefore affect both urine calcium and oxalate in the same direction. Active gut mucosal transport of calcium is facilitated by a family of cholecalciferol dependent "calcium binding proteins" (CaBP-Ds). ${ }^{41}{ }^{42}$ The fall in urine phosphate during the first six weeks of supplementary calcium (fig 3A) might theoretically mark reduced activation of cholecalciferol (that is, reduced conversion of 25-(OH)cholecalciferol to $1,25-(\mathrm{OH})_{2}$-cholecalciferol) via reduced PTH as part of a long feedback loop relating to calcium homeostasis. Although half lives of several weeks have been ascribed to CaBP-Ds, ${ }^{41}{ }^{42}$ it seems more likely that their intestinal life is measured in hours ${ }^{43}$ although they could be subject to a long feedback mechanism. Establishment of precalcium supplement values for phosphate excretion in period 3, apparent both in 24 hour urine phosphate and an increase in renal phosphate clearance (as decreased TmP/GFR), may signal resumed production of $1,25-(\mathrm{OH})_{2}$-cholecalciferol by hydroxylation of $25-(\mathrm{OH})_{2}$-cholecalciferol.

Clearly, the flaw with this speculation is the absence of evident change in $1,25-(\mathrm{OH})_{2}-$ cholecalciferol even though the equilibrium time in its production is said to be 15 hours. ${ }^{42}$ A study in normal subjects did indeed demonstrate a decline in 1,25-(OH $)_{2}$-cholecalciferol (with no PTH change) over a six to seven week period, but the calcium supplement was 2 g. $^{44}$ Deductions from our data are limited by possible differences in the cholecalciferol receptor status of individuals. Increases in the number of cholecalciferol receptors on activated lymphocytes have been found in some patients with absorptive hypercalciuria. ${ }^{45}$ A major variable affecting these data is that periods 2 and 3 covered June to mid August, the theoretical advantage being that any demonstrated 1,25$(\mathrm{OH})_{2}$-cholecalciferol reduction would be set against the period of maximum sunlight and therefore not attributable to seasonal variation as noted in other studies. ${ }^{46} 47$ The practical importance of seasonal variation in relation to this type of work is illustrated in table 1 , where mean urine calcium is $5.5 \%$ higher in light compared with dark months. The overall trend is illustrated in fig $2 \mathrm{~A}$. In period 3 (on calcium supplements), mean urine calcium rose by $10.2 \%$ compared with the period 1 baseline. Therefore, net absorption of the $500 \mathrm{mg}$ (12.5 mmol) calcium supplement was $7.8 \%$. To what extent this might encompass a 
seasonal effect is difficult to say, but net absorption might be significantly less than $7.8 \%$ of the supplementary calcium. A $7.8 \%$ (or below) net absorption of supplementary calcium is proportionally less than the "normal" one quarter net absorption. Equilibrium may not have been established (fig 2A) and longer term studies would be of interest. These discussions presuppose that oxalate is not actively transported. There is a recent suggestion that oxalate or sulphate might be coupled indirectly with the reabsorption of chloride, ${ }^{48}$ and work in the past has suggested a possible indirect role of bile acids, ${ }^{36}$ but oxalate conventionally is thought to be absorbed passively. ${ }^{49} 50$

In a previous study, we have shown that renal stone formers intrinsically have a greater degree of phosphaturia. ${ }^{22}$ This study was designed to determine whether daily calcium supplementation could reduce the phosphaturia, thereby reducing the PTH element of the stimulus to the activation of cholecalciferol, and hence the gut calcium absorbed. The reduction in phosphate excretion in period 2 of calcium supplementation is compatible with this concept, but an alternative explanation would be that calcium is simply binding phosphate in the gut. "Calcichew" contains calcium as $\mathrm{CaCO}_{3}$ and its alkaline nature would therefore favour precipitation of phosphate as calcium phosphate in the gut. The subsequent increase in urine phosphate while on the same calcium supplementation is contrary to this. There are two further considerations relating to possible phosphate precipitation. First, it could be argued that the raised urine calcium of period 3 implies that there might then be less calcium in the gut to be precipitated with phosphate, hence the rise in urine phosphate. This would require that calcium absorption improved after six weeks of calcium supplements, at a time when there is no evidence of a background (table 2; fig $2 \mathrm{~A}$ ) increase in urine calcium. Second, it could be argued that the absence of a rise in urine phosphate on stopping calcium supplements did not exclude a phosphate precipitation mechanism explaining the observations because phosphate fell in the "background" group observed over five years (that is, there was therefore relative phosphaturia in the study patients; table 2; fig 3A). The higher PTH concentrations in the study patients in periods 2 and 3 combined also favour this point. In respect of the rise in 24 hour urine calcium that occurred after six weeks of calcium supplementation, our favoured explanation is that if $\mathrm{PTH}$ is initially reduced by calcium supplementation, mobilisation of calcium from bone will be reduced, but the effect offset by a rise in the renal clearance of calcium from the direct effect of PTH on renal tubules and the calcium supplement itself. However, TmP/GFR fell in period 3, which could be interpreted to reflect higher PTH activity. Therefore, increased PTH might be responsible for an increase in urine calcium in period 3 (fig $2 \mathrm{~A}$ ) because, although the direct renal tubular effect will be to reduce calcium excretion, ${ }^{51}$ bone mobilisation will have been increased/resumed to the former value.
This, together with the calcium supplement, would raise urinary calcium.

Within its limits, we have used $\mathrm{TmP} / \mathrm{GFR}^{28}$ as the physiological index of PTH, and the absence of demonstrable changes in PTH during these periods should not be taken as negative evidence, because differences can be demonstrated between groups defined in terms of TmP/GFR that are not manifest in PTH. ${ }^{22}$ Nevertheless, there are important problems of diurnal variation with $\mathrm{TmP} / \mathrm{GFR},{ }^{52}$ with values rising from about 11:00 to 03:00 hours, but blood was taken from patients in the mornings in a non-fasting state. PTH also has the disadvantage of episodic release and a range of molecular fragments, the full physiological nature of which remain undefined. Mean serum calcium appeared to rise (not significantly) during periods 2 and 3 (fig 4A) and was even $0.07 \mathrm{mmol} /$ litre higher in combined periods 4 and 5 (off calcium supplements) than at the original baseline (period 1). The serum calcium rise off supplements was unexpected-we have not found other reports of such an effect-but in correspondence with our external quality assurance organiser it was agreed that it could not be attributed to assay drift and does broadly correspond with the PTH observations in the same periods (fig 4C). Thus, PTH is higher in periods 3 and 4 combined (off calcium supplements) than periods 2 and 3 combined (on calcium). This is not reflected in increased phosphaturia or decreased $\mathrm{TmP} / \mathrm{GFR}$, but a comparison of fig $3 \mathrm{~A}$ and table 2 suggests that phosphaturia is "hidden" by a seasonal decline in urine phosphate and that a relative phosphaturia does indeed exist. Basal PTH values have been shown to be seasonally dependent, with higher values seen after winter, ${ }^{46}$ but the observed variables and potential variables are such that we have not attempted to speculate further and we present the information within its many limitations as found. Oral calcium has also been given to children in what the authors described as the first study of short term and "long term" (one week) calcium loading in idiopathic hypercalciuria. ${ }^{47}$ No change was evident in $1,25-(\mathrm{OH})_{2}$-cholecalciferol and they hypothesised that "autonomously raised" 1,25$(\mathrm{OH})_{2}$-cholecalciferol production is a possible mechanism for idiopathic hypercalciuria. We note (fig 3A) the rise in urine phosphate, after an initial decline, during the period of supplementation and suggest that it might be part of a long feedback loop regulating calcium metabolism, which might even relate to the metabolism of cholecalciferol. A fundamental basic problem in attempting to explain the data in this type of study is the number of variables and we do not know whether we are in fact witnessing the putative phosphaturic hormone ${ }^{28-30}$ at work.

We think that these findings are of relevance to clinical practice. The correlation between urine calcium and oxalate suggests that programming of gut mucosal transport of calcium is a key to the relation between calcium and oxalate in urine. The reduction of mucosal calcium transport has two benefits: not only is 
there less calcium in urine but, much more importantly, less oxalate. Our study suggests that there may not be a "penalty" in terms of a raised urine calcium oxalate product from a modest regular calcium supplement. With further calcium supplement increments there may be a point where, despite an increase in the normal calcium intake, there is a possible net decrease in the supersaturation of urine with respect to calcium oxalate. This factor may theoretically be three to five, corresponding to our "primitive" calcium intake if vitamin D supplements are excluded. Furthermore, as sustained calcium intake increases, baseline gut calcium rises correspondingly. If mucosal transport of calcium is "downregulated" by calcium supplements in this manner, natural surges in dietary calcium might produce less sharp peaks than they might otherwise do. More importantly, more calcium will be available in the gut to chelate oxalate, with possible benefits upon urine supersaturation. With an "all or nothing element" to the formation of crystals, even a modest reduction in urine saturation below a critical threshold may be crucial. We assume that it is the height of the peaks as opposed to the width that is critical in concentration terms. In essence, patients might have the advantage of absorbing more slowly even if they absorb no less. Integrated values over 24 hours matter less than their peak concentrations at any point in time. Superimposed upon these considerations are circadian rhythms of calcium, oxalate, and phosphate, which have been shown to affect saturation and lithogenic risk. ${ }^{53-55}$ We recommend that these factors should be explored in terms of the effects of calcium supplementation.

As a concluding observation, we note that vitamin $\mathrm{D}$ is integral to the regulation of calcium metabolism and ask whether fortification of the national diet with vitamin $\mathrm{D}$ and public interest in vitamin $\mathrm{D}$ supplements does not have a more important underlying role in the generation of some renal stones than the literature would suggest. We recommend that this suggestion should be considered further.

We would like to thank Mrs P Walsh for her very expert administrative help with our study.

1 Eaton SB, Nelson DA. Calcium in evolutionary perspective. Am f Clin Nutr 1991;54:281S-7S.

2 Coe Fl, Oarjs JH, Asplin JR, The pathogenesis and treatment of kidney stones. N Engl F Med 1992;327:1151-2.

3 Sierakowski R, Finlayson B, Landes RR, et al. The frequency of urolithiasis in hospital discharge diagnoses the United States. Investig Urol (Berl) 1978;15:438-41.

4 Johnson CM, Wilson DM, O'Fallon WM, et al. Renal stone epidemiology: a 25 year study in Rochester, Minnesota. Kidney Int 1979;16:624-31.

5 Norlin A, Lindell B, Granberg P-O, et al. Urolithiasis: a study of it's frequency. Scand F Urol Nephrol 1976;10:150-3.

6 Yoshida O, Okada Y. Epidemiology of urolithiasis in Japan: a chronological and geographical study. Urol Int 1990;45: 104-11.

7 Curhan GC, Willett WC, Rimm EB, et al. A prospective study of dietary calcium and other nutrients and the risk of symptomatic kidney stones. N Engl F Med 1993;328:833-8.

8 Marshall RW, Cochran M, Robertson WG, et al. The relation between the concentration of calcium salts in the urine and renal stone composition in patients with calcium-containing renal stones. Clin Sci 1972;43:433-41.

9 Lehmann J, Jr, Pleuss JA, Worcester EM, et al. Urinary oxalate excretion increases with body size and decreases with increasing dietary calcium. Kidney Int 1996;49:200-8.

10 Holmes RP, Goodman HO, Assimos DG. Dietary oxalate and its intestinal absorption. Scanning Microsc 1995;9: $1109-18$.
11 Masai $\mathrm{M}$, Ito $\mathrm{H}$, Kotake $\mathrm{T}$. Effect of dietary intake on urinary oxalate excretion in calcium renal stone formers. $\mathrm{Br}$ f Urol 1995;76:692-6.

12 Leonetti F, Dussol B, Berthezene P, et al. Dietary and urinary risk factors for stones in idiopathic calcium stone formers compared with healthy subjects. Nephrol Dial Transplant 1998;13:617-22.

13 Caudarella R, Rizzoli E, Buffa A, et al. Comparative study of the influence of 3 types of mineral water in patients with idiopathic calcium lithiasis. F Urol 1998;159:658-63.

14 Curhan GC, Willett WC, Speizer FE, et al. Comparison of dietary calcium with supplemental calcium and other nutrients as factors affecting the risk for kidney stones in women. Ann Intern Med 1997;126:497-504.

15 Messa P, Marangella M, Pagani L, et al. Different dietary calcium intake and relative supersaturation of calcium oxalate in the urine of patients forming renal stones. Clin Sci 1997;93:257-63.

16 Liebman M, Chai W. Effect of dietary calcium on urinary oxalate excretion after oxalate loads. Am F Clin Nutr 1997; 65:1453-9.

17 Messa P, Marangella M, Paganini L, et al. Different dietary calcium intake and relative supersaturation of calcium oxalate in the urine of patients forming renal stones. Clin Sci 1997;93:259-63.

18 Fraser DR. Fat soluble vitamins. Lancet 1995;345:104-7.

19 Taylor WH. Renal calculi and self-medication with multivitamin preparations. Clin Sci 1972;42:515-22.

20 Giannini S, Nobile M, Castrignano R, et al. Possible link between vitamin $\mathrm{D}$ and hyperoxaluria in patients with renal stone disease. Clin Sci 1993;84:51-4.

21 Robertson WG, Peacock M. The cause of idiopathic calcium stone disease: hypercalciuria or hyperoxaluria? Nephron 1980;26:105-10.

22 Williams CP, Child DF, Hudson PR, et al. Inappropriate phosphate excretion in idiopathic hypercalciuria: the key to a common cause and future treatment? f Clin Pathol 1996; 49:881-8

23 Alvarez-Arroyo MV, Traba ML, Rapado A, et al. Correlation between 1.25 dihydroxyvitamin $\mathrm{D}$ serum levels and fractional rate of intestinal calcium absorption in hypercalciuric nephrolithiasis. Role of phosphate. Urol Res 1992;20: 96-7.

24 Portale AA, Halloran BP, Murphy MM, et al. Oral intake of phosphorous can determine the serum concentration of phosphorous can determine the serum concentration of 1,25-dihydroxyvitamin D by determining
rate in humans. F Clin Invest 1987;77:7-12.

25 Crook M, Swaminathan R. Disorders of plasma phosphate and indications for it's measurement. Ann Clin Biochem 1996;33:376-96.

26 Ho SC, MacDonald D, Chan C, et al. Determinants of serum 1,25-dihydroxyvitamin D concentration in healthy premenopausal subjects. Clin Chim Acta 1994;230:21-33.

27 Walton RJ, Bijvoet OLM. Nomogram for derivation of renal threshold phosphate concentrations. Lancet 1975;ii:309-

8 Payne RB. Renal tubular reabsorption of phosphate (TmP/ GFR): indications and interpretation. Ann Clin Biochem 1998;35:201-6.

29 Cai Q, Hodgson SF, Kao PC, et al. Brief report: inhibition of renal phosphate transport by a tumour product in a patient with oncogenic osteomalacia. N Engl f Med 1994;330: $1645-9$.

30 Econs MJ, Drezner MK. Tumour-induced osteomalaciaunveiling a new hormone [editorial]. $N$ Engl $f \mathrm{Med}$ 1994;330:1679-81.

31 Madsen KL, Tavernini MM, Yachimec C, et al. Stanniocalcin: a novel protein regulating calcium and phosphate transport across mammalian intestine. $A m \mathcal{F}$ Physiol 1998;274:G96-102.

32 Hallson PC, Kasidas GP, Rose GA. Urinary oxalate in summer and winter in normal subjects and in stone-forming patients with idiopathic hypercalciuria, both untreated and treated with thiazide and/or cellulose phosphate. Urol Res 1976;4:169-73.

33 Hallson PC, Rose GA. Seasonal variations in urinary crystals. Br F Urol 1977;49:277-84.

34 Robertson WG, Gallagher JC, Marshall DH, et al. Seasonal variations in urinary excretion of calcium. BMF 1974;4: 436-7.

35 Robertson WG, Peacock M, Marshall RW, et al. Seasonal variations in the composition of urine in relation to calcium stone-formation. Clinical Science and Molecular Medicine 1975;49:597-602.

36 Rose GA, Westbury EJ. Seasonal and geographic variations in urinary composition in England, Scotland and Wales. Urol Res 1979;7:235-40.

37 Robert M, Roux JO, Bourelly F, et al. Circadian variation in the risk of urinary calcium oxalate stone formation. $\mathrm{Br} \mathcal{F}$ Urol 1997;74:294-7.

38 Juuti M, Heinonen OP, Alhava EM. Seasonal variation in urinary excretion of calcium, oxalate, magnesium and phosphate on free and standard mineral diet in men with urolithiasis. Scand $\mathcal{F}$ Urol Nephrol 1981;15:137-41.

39 Walters JRF. Absorption and malabsorption of calcium and vitamin D. In: Bouchier IAD, Allan RN, Hodgson HJF, et al, eds. Gastroenterology-clinical science and practice, 2nd ed. London: WB Saunders, 1993:433-7.

40 Kato T, Yanagawa M. Dietary control for outpatients in urinary stone clinic. Hinyokika Kiyo 1993;39:593-98.

41 Gross M, Kumar R. Physiology and biochemistry of vitamin D-dependent calcium binding proteins. Am f Physiol 1990; 259:f195-209. 
42 Guyton AC, Hall TE. Parathyroid hormone, calcitonin, calcium and phosphate metabolism, vitamin $\mathrm{D}$, bone and
teeth. In: Guyton AC. Textbook of medical physiology, 8 th ed. teeth. In: Guyton AC. Textbook of medical physi

43 Norman AW, Friedlander EJ, Henry HL. Determination of the rates of synthesis and degradation of vitamin D-dependent chick intestinal and renal calcium-binding proteins. Arch Biochem Biophys 1981;206:305-17.

44 Berlin T, Bjorkhem I. Effect of calcium intake on serum levels of 25-hydroxyvitamin D3. Eur f Clin Invest 1988;18:52 5.

45 Lloyd SE, Pearce SHS, Fisher SE, et al. A common molecular basis for three inherited kidney stone diseases. Nature 1996;379:445-9.

46 Gullemant J, Gullemant S. Acute PTH response to oral calcium load and seasonal variation of vitamin D status in healthy young adult subjects. Eur f Clin Nutr 1996;50:46972 .

47 Veenhuizen L, Donkerwolke RAMG. Role of 1,25 dihydroxyvitamin $D$ production in idiopathic hypercalciudihydroxyvitamin D production in idiopa
ria. Child Nephrol Urol 1991;11:69-73.

48 Brandle E, Bernt U, Houtmann RE. In situ characterisation of oxalate transport across the basolateral membrane of the proximal tubule. Pflugers Archiv 1998;435:840-9.
49 Caspary WF. Intestinal oxalate absorption I. Absorption in vitro. Res Exp Med 1977;171:13-24.

50 Verkoelen CF, Romijn JC, de Bruijn WC, et al. Absence of a transcellular oxalate transport mechanism in LCC-PK1 and MDCK cells cultured on porous supports. Scanning Microsc 1993;7:1031-8.

51 Aurbrach GD, Marx SJ, Spiegel AM. Parathyroid hormone, calcitonin and the calciferols. In: Wilson JD, Foster DW, eds. Williams textbook of endocrinology, 8th ed. Philadelphia: WB Saunders, 1992:1397-1476.

52 Kemp GJ, Blumsohn A, Morris BW. Circadian changes in plasma phosphate concentration, urinary phosphate excretion and cellular phosphate shifts. Clin Chem 1992:38:400-

53 Vahlensieck EW, Bach D, Hesse A. Circadian rhythm of lithogenic substances in urine. Urol Res 1982;10:195-203.

54 Robert M, Roux JO, Bourelly F, et al. Circadian variation in the risk of urinary calcium oxalate stone formation. $\mathrm{Br} F$ Urol 1997;74:294-7.

55 Ogawa Y. Circadian rhythms of urinary saturation levels of calcium oxalate and calcium phosphate in normal male individuals. Hinyokika Kiyo 1993;39:785-9. 